\title{
Evaluation of Breast Lump by Fine Needle Aspiration Cytology
}

\author{
Poudel $\mathbf{S}^{\prime *}$, Ranabhat S', Parajuli B', Pun G'
}

'Lecturer, Department of Pathology, Gandaki Medical College \& Teaching Hospital, Pokhara, Nepal

\section{Keywords}

Breast lump, Fibroadenoma,

Fine needle aspiration cytology,

Histopatholgy.

\section{Corresponding author \\ *Dr. Suman Poudel, MD \\ Lecturer, Department of Pathology \\ Gandaki Medical College \& Teaching \\ Hospital, Pokhara, Nepal \\ Email: batigsu@gmail.com}

\begin{abstract}
Introduction: Fine needle aspiration cytology (FNAC) is the important part of triple assessment in diagnosing the palpable breast lump. It categorizes the lesion into benign, malignant and its subtypes. It can also identify the residual diseases after treatment.
\end{abstract}

Methods: It was a cross sectional descriptive study of cases of breast lump carried out during June 2015 to May 2016 in the Department of Pathology, Gandaki Medical College Teaching Hospital, Pokhara, Nepal. All the patients presenting in Pathology Department with history of breast lump were examined in detail. FNAC was done by standard procedure; smears were prepared and stained with Giemsa and pap for evaluation. Histopathology slides were stained with hematoxylin and eosin stain and evaluated by pathologists in Gandaki Medical College Teaching Hospital.

Results: The study showed that, fibroadenoma of breast is the commonest benign lesion among the young populations. Only 13.11\% of breast lump is malignant in the elderly population.

Conclusion: FNAC is one of the safest and cheapest procedure that can be done in outpatient department for the diagnosis of breast lump. And there is no significant difference in diagnosis made by FNAC and histopatholgy examination.

\section{INTRODUCTION}

Lump in breast, whether benign or malignant is the main cause of anxiety to the patient and her family members. Breastcarcinoma is the most common malignantneoplasm and the leading cause of death from cancer in women, with more than one million cases occurring worldwide annually ${ }^{1,2}$. Though histopathological diagnosis is universally accepted confirmatory mode of diagnosis and follow up, fine needle aspiration cytology (FNAC) of breast lumps is an important part of triple assessment (Clinical examination, imaging, and FNAC) of palpable breast lumps ${ }^{3}$. It bridges the gap between clinical evaluation and final surgical pathological diagnosis in majority of cases and helps to reduce unwanted surgeries ${ }^{4}$. Scope of FNA has now extended into identifying the subtypes of benign, malignant lesions and residual disease for the purpose of planning the therapeutic protocol and eventual followup 5 .

The present study is intended to evaluate the frequency of distribution of various lesions of palpable breast lumps among the patients visiting Gandaki Medical College Teaching Hospital, Pokhara, Nepal.

\section{METHODS}

It was a cross sectional descriptive study of cases of breast lump carried out during June 2015 to May 2016 in the Department of Pathology, Gandaki Medical College 
Teaching Hospital, Pokhara. All the patients presenting in our department with history of breast lump were examined in detail. FNAC was done following the standard procedure with 22 gauge needle by aspiration technique. From the sample obtained at least two dry and two wet smears were prepared and stained with Giemsa and Papanicolau stains respectively. In case of cystic lesions fluid was aspirated first followed by re-aspiration from the solid area. In difficult cases, image guided FNAC was done. The smears were evaluated by consultant pathologists and the final diagnoses of the FNAC were reported. Findings of FNAC were correlated with data from histopathology records wherever possible. For the histopathology diagnosis the standard protocol was followed. The tissue was formalin fixed, processed and paraffin embedded. The slides were stained with hematoxylin and eosin stain. The cytomorphological details, FNAC diagnosis and histopathology data were entered in the microsoft excel 2010 and study variables were statistically analyzed by statistical package for social service (SPSS) 16.0.

\section{RESULTS}

A total of 61 cases were evaluated with preponderance of female population (59). The most common age group presented with breast lump was 11 - 30 years. All of them present with benign lesions most commonly fibroadenoma comprising of $47.54 \%$. The malignant breast lumps were found in $13.11 \%$ of patients ranging from 50 - 70 years. Though only 15 cases after FNAC undergo biopsy, there was no significant difference between the diagnosis made by FNAC and histopathology study.

Fig 1: Frequency of lesions according to sex

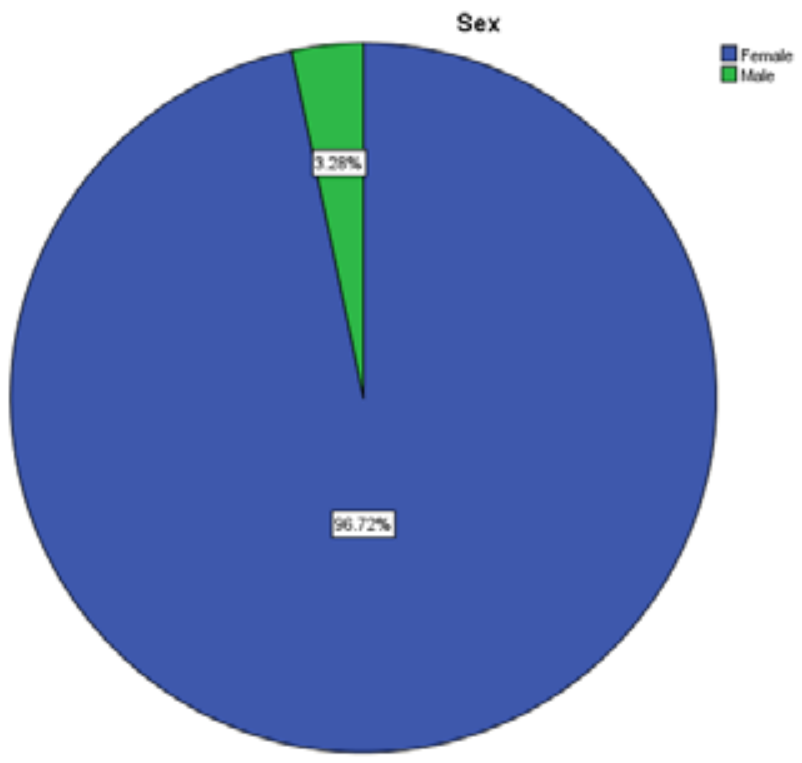

In our study, there was preponderance of female population with breast lump.

Fig 2: Frequency of breast lesions diagnosed by FNAC

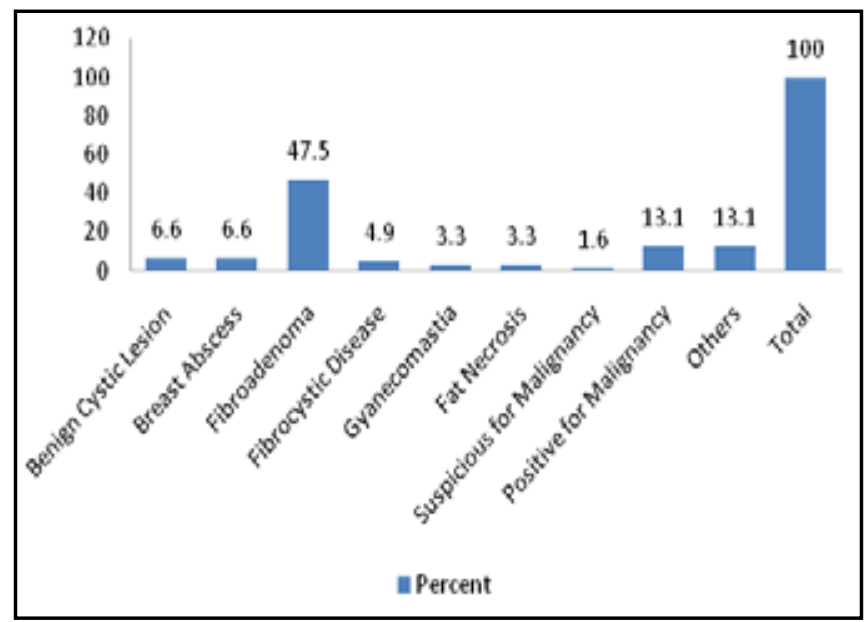

Out of 61 cases, the most common lesion was fibroadenoma comprising $47.54 \%$ and the malignant cases were few comprising only $13.11 \%$. Cases categorised as suspicious for malignancy which required biopsy for confirmation of diagnosis were $1.6 \%$.

Table 1: Biopsy status of the breast lesions after FNAC diagnosis

\begin{tabular}{lcc}
\hline \multicolumn{1}{c}{ Biopsy status after FNAC } & Frequency & Percentage \\
\hline Biopsy not done & 46 & $75.4 \%$ \\
Biopsy done & 15 & $24.6 \%$ \\
Total & 61 & $100 \%$ \\
\hline
\end{tabular}

Out of 61 cases of FNAC only 15 (24.6\%) undergo biopsy examination.

Table 2: Correlation of FNAC diagnosis with biopsy diagnosis

\begin{tabular}{ccccc} 
& \multicolumn{3}{c}{ Biopsy(DX) } & \\
\cline { 2 - 4 } Fibrocystic disease & $\begin{array}{c}\text { Invasive } \\
\text { ductal } \\
\text { carcinoma } \\
\text { NOS }\end{array}$ & $\begin{array}{c}\text { Fibroad- } \\
\text { enoma }\end{array}$ & Total \\
\hline \multicolumn{1}{c}{ Fibroadenoma } & 0 & 0 & 6 & 6 \\
$\quad \begin{array}{l}\text { Fibrocystic } \\
\text { disease }\end{array}$ & 1 & 0 & 1 & 2 \\
$\begin{array}{l}\text { FN } \\
\text { (DX) } \begin{array}{l}\text { Suspicious for } \\
\text { malignancy }\end{array}\end{array}$ & 0 & 1 & 0 & 1 \\
$\quad \begin{array}{l}\text { Positive for } \\
\text { malignancy }\end{array}$ & 0 & 6 & 0 & 6 \\
Total & 1 & 7 & 7 & 15 \\
\hline
\end{tabular}

Out of 15 cases, one case diagnosed as suspicious for malignancy by FNAC was confirmed by biopsy and it came out to be malignant. 
Fig 3: Fibroadenoma (Giemsa 100X) (Smears show both epithelial component in cohesive clusters and nests along with fibromyxoidstroma in the background of bare nuclei)

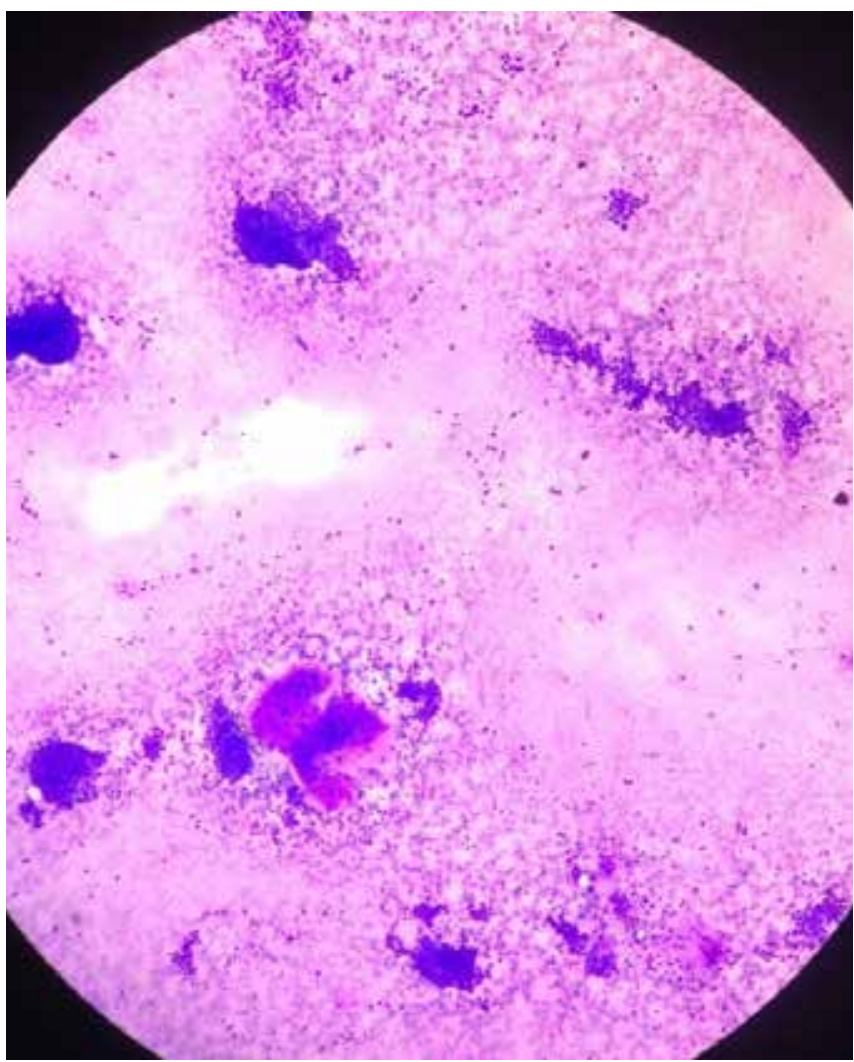

Fig 5: Fibroadenoma (H \& E 100X) (Section shows pericanalicular and intracanalicular pattern of ducts along with stromal proliferation)

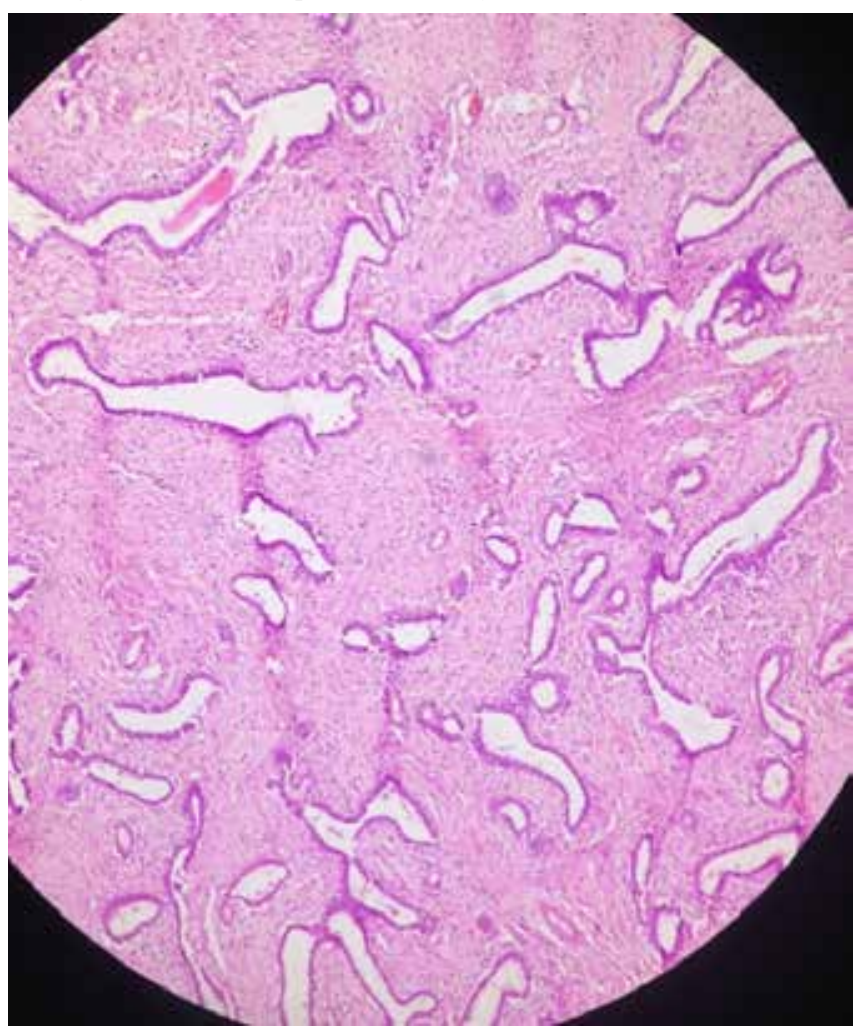

Fig 6: Positive for malignancy (Giemsa $100 \mathrm{X}$ ) (Cellular smear with highly pleomorphic cells, high nucleus to cytoplasm ratio, hyperchromatic nucleus, prominent nucleoli and moderate amount of cytoplasm. Absence of myoepithelial cells)

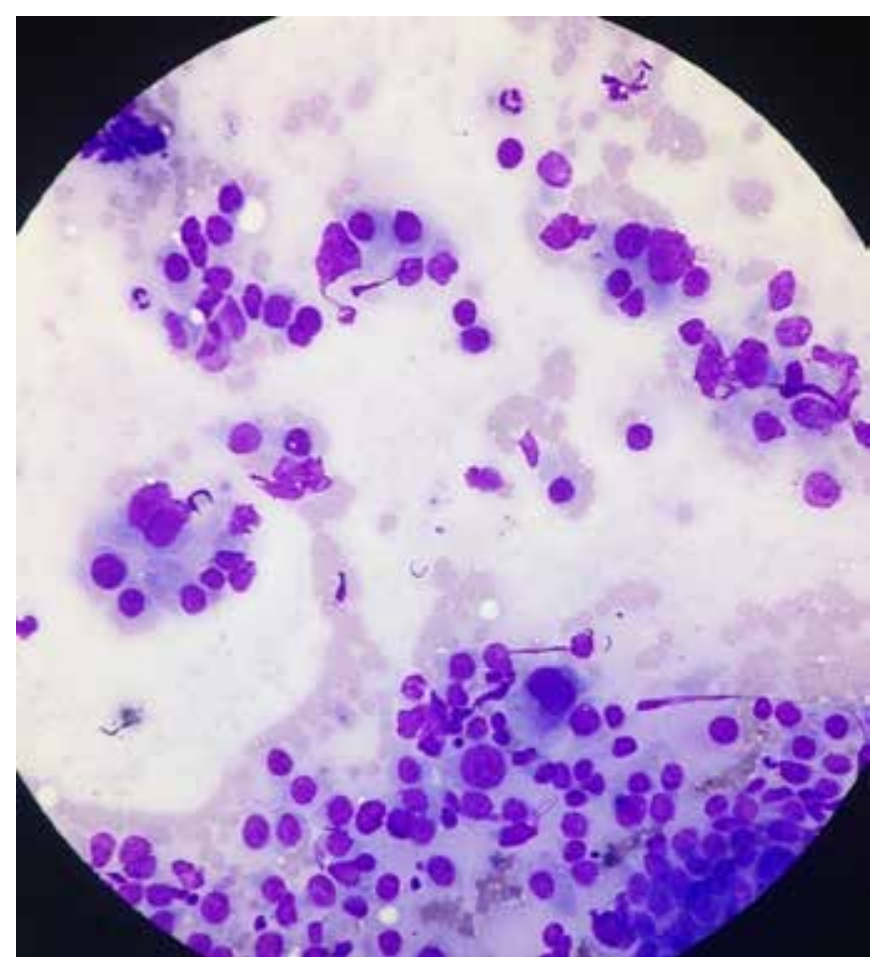

Fig 7: Invasive carcinoma NOS breast (H \& E 400X) (Tumor cells infiltrating desmoplasticstroma)

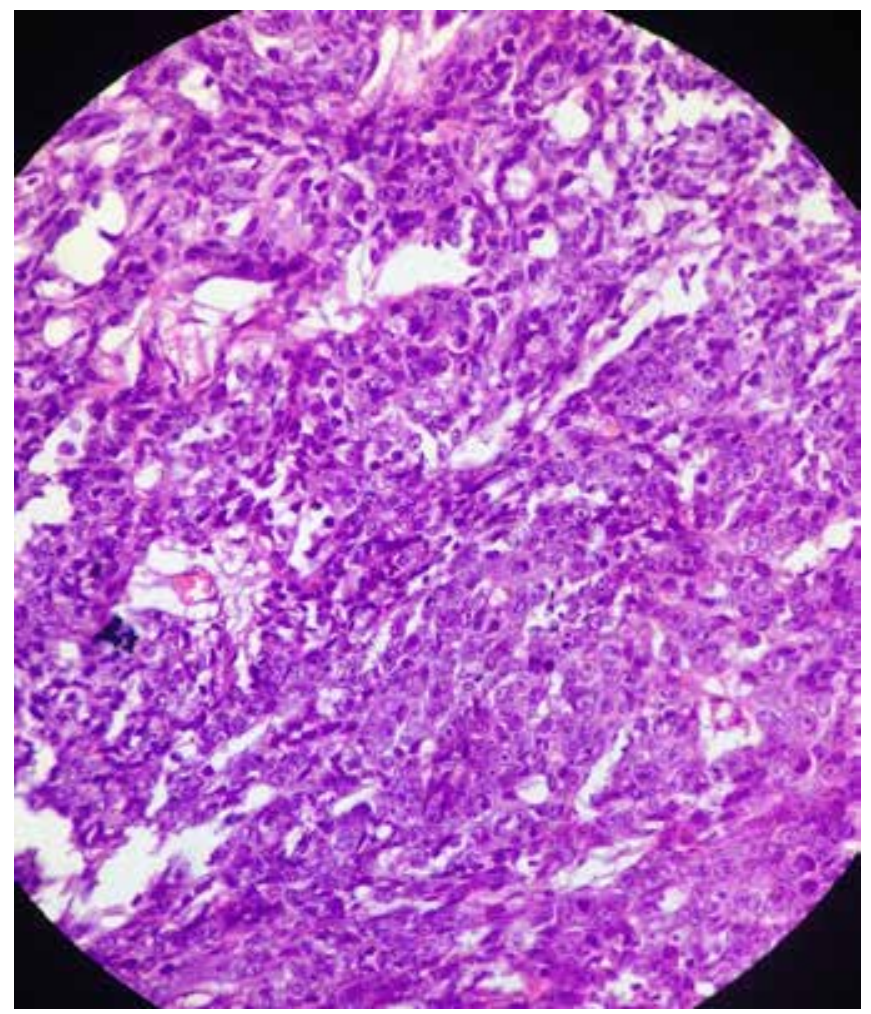




\section{DISCUSSION}

Fine-needle aspiration cytology is a rapid and effective method for the primary categorization of palpable breast lumps into benign, malignant, atypical, suspicious, and unsatisfactory categories ${ }^{6}$. The most significant advantage of FNAC is the high degree of accuracy, rapid results, and a less invasive procedure than a tissue biopsy $^{7}$. The breast lesions (benign or malignant) were common among females when compared to males. In our study $96.72 \%$ were female patients. The most common age group presented with breast lump was 11 - 30 years and all of the lumps were benign which is similar to the study done by Pudasaini $\mathrm{S}^{8}$. The most common benign breast lesion was fibroadenoma comprising 47.54\% of cases studied. These findings are justified by similar findings stated by Panjavni Sl et al ${ }^{9}$. The smears show both epithelial and stromal component as a diagnostic component and all being benign (Fig 3). According to a study conducted by Elmadhoun WM et $a l^{10}$ and Islam $\mathrm{A}^{11}$, as compared to benign lesions, the malignant lesions were few and occurs commonly after 35 years of age. In our study also, as compared to benign lesions the malignant lesions comprised of only $13.11 \%$. The malignant breast lumps were seen after the fourth decade of life. The cytomorphology of malignant lump show pleomorphic cells with high nucleus to cytoplasm ratio, hyperchromatic nucleus, prominent nucleoli and absence of myoepithelial cells (Fig 6).

The other lesions diagnosed by FNAC were fat necrosis, benign cystic lesions, breast abscess, gynaecomastia etc. Cases categorized under suspicious for malignancy that requires histopathological examination for the confirmation of diagnosis were $1.64 \%$.

Out of 61 cases of FNAC, only 15 cases undergo biopsy which comprises $24.6 \%$ of total cases. The role of FNAC in diagnosing the malignant cases is very effective. In our study the sensitivity and specificity of FNAC in diagnosing malignant lesions were $100 \%$ and $85.7 \%$ respectively. There were no false positive cases while false negative cases accounted for $14.3 \%$. These findings are similar to other studies ${ }^{2,12,13}$. The FNAC results are more reliable regarding malignant lesions; however the category of "suspicious for malignant lesions" needs histopathological evaluation before performing surgical measures ${ }^{7}$. In our study, the histopathology features of fibroadenoma and invasive carcinoma NOS are demonstrated in figures 5 and 7 respectively.

\section{CONCLUSION}

FNAC is the safest and the most economical pre-operative diagnostic test for palpable breast lump. There is predominance of fibroadenoma among the benign breast lesions and it is seen mainly in the young population. The malignant breast lumps were seen after the age of 40 years in our study. Though the number of cases that underwent histopathology examination were few, our study showed that, there was no significant difference between the diagnosis made by FNAC and histopathology examination.

\section{REFERENCES}

1. Islam SRM. Fine needle aspiration cytology of palpable breast lump: A study of 1778 cases. Surg Curr Res. [Internet] 2013; [cited 2016 Aug 10]; s12(01). Available from: http://www.omicsonline. org/fine-needle-aspiration-cytology-of-palpablebreast-lump-a-study-of\%201778-cases-2161-1076. S12-001.php?aid=12017

2. Rahman MZ, Sikder AM, Nabi SR. Diagnosis of breast lump by fine needle aspiration cytology and mammography. Mymensingh Med J. 2011 Oct; 20(4): 658-64.

3. Tiwari M. Role of fine needle aspiration cytology in diagnosis of breast lumps. Kathmandu Univ Med J. 2007 Jun; 5(2): 215-7.

4. Poudel S. Cytopathological evaluation of thyroid by fine needle aspiration cytology and correlation with T3 T4 and TSH levels. http://www.ucms.com.np/ images/journals/issue12/08.pdf [Internet]. [cited 2016 Aug 10]; Available from: http://www.ucms. com.np/images/journals/issue12/08.pdf

5. Chandanwale SS, Gupta K, Dharwadkar AA, Pal S, Buch AC, Mishra N. Pattern of palpable breast lesions on fine needle aspiration: A retrospective analysis of 902 cases. J Life Health. 2014; 5(4): 186-91.

6. Sankaye SB, Dongre SD. Cytological study of palpable breast lumps presenting in an Indian rural setup. Indian J Med Paediatr Oncol. 2014; 35(2): 159-64.

7. Bukhari MH, Arshad M, Jamal S, Niazi S, Bashir S, Bakhshi IM et al. Use of Fine-needle aspiration in the evaluation of breast lumps. Pathol Res Int. [Internet] 2011 Jun 21; [cited 2016 Aug 10]; 2011. Available from: http://www.ncbi.nlm.nih.gov/pmc/articles/ PMC3135154/ 
8. Pudasaini S, Talwar OP. Study of fine needle aspiration cytology of breast lumps and its histopathological correlation in Pokhara Valley. Nepal Med Coll J. 2011 Sep; 13(3): 208-12.

9. Panjvani SI, Parikh BJ, Parikh SB, Chaudhari BR, Patel KK, Gupta GS et al. Utility of fine needle aspiration cytology in the evaluation of breast lesions. J Clin Diagn Res. 2013 Dec; 7(12): 2777-9.

10. Elmadhoun WM, Almobarak AO, Ibrahim AM, Bushara S, Noor SK, Husain NEOS et al. Cytomorphology of palpable breast lesions: Diagnostic utility of FNAC in a developing country. Diagn Cytopathol. 2015 Oct; 43(10): 825-9.
11. Islam A, Khondker NS, Rahman S, Reza E, Mahamud MM, Shaon SA et al. A Comparative Study between FNAC and histopathology in diagnosis of breast lump. Mymensingh Med J. 2015 Jul; 24(3): 486-91.

12. Muddegowda PH, Lingegowda JB, Kurpad R, Konapur P, Shivarudrappa A, Subramaniam P. The value of systematic pattern analysis in FNAC of breast lesions: 225 cases with cytohistological correlation. J Cytol Indian Acad Cytol. 2011; 28(1): 13-9.

13. Saleh FM, Ansari NP, Alam O. Comparison between fine needle aspiration cytology with histopathology to validate accurate diagnosis of palpable breast lump. Mymensingh Med J. 2012 Jul; 21(3): 450-5. 